\title{
Remanufacturing Strategies Based on Value Analysis of Product Life Cycle
}

\author{
Zhou Ziqiang $^{1,2, *}$, Dai Guohong ${ }^{1,2}$, Zhang Xiangyan ${ }^{2}$ and Zhang Yongjian ${ }^{1,2}$ \\ ${ }^{I}$ School of Mechanical Engineering, Changshu Institute of Technology, Changshu, Jiangsu, 215500 China; \\ ${ }^{2}$ Jiangsu Key Laboratory of Recycling and Reuse Technology for Mechanical and Electronic Products, Changshu, \\ Jiangsu, 215500 China
}

\begin{abstract}
In order to improve the benefits of remanufacturing of end-of-life (EOL) products, the remanufacturability of these products should be analyzed. However, it is insufficient to evaluate the remanufacturability just according to the feasibility of technologies. The remanufacturability of EOL products should also be analyzed from the view of product life cycle. In this paper, the remanufacturability is discussed according to the signification of service lifecycle and market lifecycle, which are sub concepts of product life cycle. The cost and profit model of remanufacturing is also proposed from the view of product life cycle. In addition, preconditions and strategy are presented for direct remanufacturing, upgrading remanufacturing and component remanufacturing. Finally, three case studies are performed to verify the above mentioned remanufacturing strategies based on the analysis of EOL products.
\end{abstract}

Keywords: Product life cycle, Remanufacturing, Remanufacturability, Recycling of end-of-life products.

\section{INTRODUCTION}

With the ever growing concerns from the whole society on environment and natural resources, remanufacturing has been extensively considered to have enormous impact on resource conservation and reduction of energy consumption. According to the general definition, remanufacturing is a recovery of EOL (end of life) products through dismantling, cleaning, surface repair, testing, assembly and/or other processes, and through remanufacturing the final performance recovers or exceeds that of the original products. However, the remanufacturing of the whole product or all of its components is not required or desirable, since this is limited by the cost of manufacturing process and the market demands on remanufactured products. Therefore, the remanufacturing of EOL products or components becomes necessary and the related remanufacturing companies are able to survive and develop, only when the remanufacturing meets the cost requirements and market demands.

Recently, researchers have conducted studies on the remanufacturability analysis of EOL products from various aspects. Liu et al. analyzed the constitution of evaluation indexes for the remanufacturability of waste products, and derived the remanufacturability indexes of EOL products using analytic hierarchy process and fuzzy weights [1]. Ramesh et al. presented a decision making framework for remanufacturing in order to assist in industrial remanufacturing initiatives [2]. Du et al. investigated the remanufacturing model of machine tools [3]. Mattias et al.

*Address correspondence to this author at the School of Mechanical Engineering, Changshu Institute of Technology, Changshu, Jiangsu, 215500, P.R. China; Tel: +86 512 52251595; Fax: +86 512 52251595; E-mail: zzq rrme@163.com
Presented life Cycle Assessment methodology for the environmental validations in remanufacturing [4]. Manuel et al. also applied life-cycle assessment for analysis of environmental impacts on remanufacturing wind turbines [5]. Zakri et al. Proposed a case based reasoning approach for remanufacturing evaluation [6]. Sabharwal studied the generalized cost constitution and its assessment methods for the remanufacture of waste products. Their research covered four aspects: collection of waste products, process indicators, material recovery indicators and market indicators, based on which a comprehensive assessment was performed by combining fuzzy theory and graph model. Based on the process flow of product remanufacture [7]. Zhang et al. proposed evaluation indexes for the processes of replacement, disassembly, reassembly, testing, inspection, repair and cleaning. A comprehensive index model for remanufacturing was established accordingly in their work [8]. Hyun et al. studied the evaluation and decision model of the remanufacturing strategy of EOL products with environmental constraints, in which the influence of remanufacturing process on the environment was minimized [9]. Swapnil analyzed the constituent elements of remanufacturability from the perspective of product design, including the developed evaluation criteria and quantitative models of the disassembly indicators, detection indicators, reusability indicators and environmental indicators [10]. Michael et al. presented a novel modeling approach for evaluating the uncertainty of part failures within the remanufacturing process, its impact on economic and environmental performance also evaluated [11]. Kaizhou et al. proposes a hybrid discrete harmony algorithm for solving the re-processing scheduling problem in pump remanufacturing [12]. Boustani et al. Discussed economic con- 
sequences of appliance remanufacturing products compared with purchasing new one [13]. Farhad et al. presented a general formulation for remanufacturing systems, and estimated the flow rate and composition of good returned parts [14].

Most of the studies mentioned above are mainly focused on the analyzing and evaluating of remanufacturability of products from the point of view of technology, while there is a lack of analysis on the full life cycle of the products themselves. From the definition of the product life cycle, its concept can be divided into the service life cycle and the market life cycle, both of which have significant impact on the product remanufacturing. Therefore, the remanufacturability for EOL products should to be evaluated under this circumstance; otherwise, it would be no meaning to remanufacture the EOL product just according to the feasibility of technology.

\section{CONTENTS AND TYPES OF PRODUCT LIFE CYCLE}

Since the emergence of concept of product life cycle, which mainly focused on the market perspective, namely the market life cycle of products. It refers to the processes of development, production, growth, maturity, decline and complete withdraw of products (as shown in Fig. 1). Later, with the emergence of concept of sustainable development, the meaning of product life cycle was extended to the service life cycle of specific products. The whole cycling process of a product, including requirement analysis, design, manufacture, service, maintenance and eventual recycling, is generally defined as the service life cycle of the product. The market life cycle of products generally refers to the market process of product categories, while the service life cycle of products means the whole process of a specific products, including service, decommissioning and recycling. Therefore, these two processes do not coincide in either content or period.

There are significant differences between the market cycle and the service cycle of products in various areas. Several broad categories of products have never entered decline stage since their emergence, while only the subdivision products are continuously upgraded with the development of technology. Specific examples of these products include automobiles, elevators, etc. Obviously, technology development may bring about the aforementioned market cycles of several components in a broad category of products. During this process, some products are forced to withdraw from the market because of the emergence of new substitutes or inventions. For example, Walkman tape player (a famous product invented by SONY) was later replaced by more compact MP3 players. The Walkman players produced in the early phase were able to cover all its service life, but the ones produced at the period of market replacement period were decommissioned in advance with incomplete service life. The essence lies in the fact that the consumption life cycle of the product has ended. Even if the products at this stage can be effectively remanufactured, there is no practical significance in terms of market. Therefore, the remanufacturability and remanufacturing strategies of EOL products should be comprehensively analyzed and evaluated from the perspective of the product life cycle.

\section{REMANUFACTURING STRATEGIES BASED ON THE PRODUCT LIFE CYCLE}

The objective of remanufacturing is to make EOL products re-enter the service stage after recovery of quality and function. With social development and technological upgrade, specific products achieving certain function have also been continuously updated. To analyze the remanufacturability of specific EOL products, a comprehensive analysis based on remanufacturing product's market environment, customers acceptance, etc., needs to be performed besides the analysis of specific technical processes. To this end, a model of remanufacturing process based on product life cycles was proposed in this study (shown in Fig. 2). The service life cycle and the market life cycle of products were jointly analyzed, which provides a basis for the remanufacturability analysis of EOL products.

In Fig. (2), the product subgeneration resulted from upgrading are represented by I, II, III, etc. Take automobile as an example, although the broad product category has been developing steadily after entering the maturity period, automobile manufacturers usually launch a new-generation model every three to five years following the changes in consumers' ideas and marketing strategies. Compared with

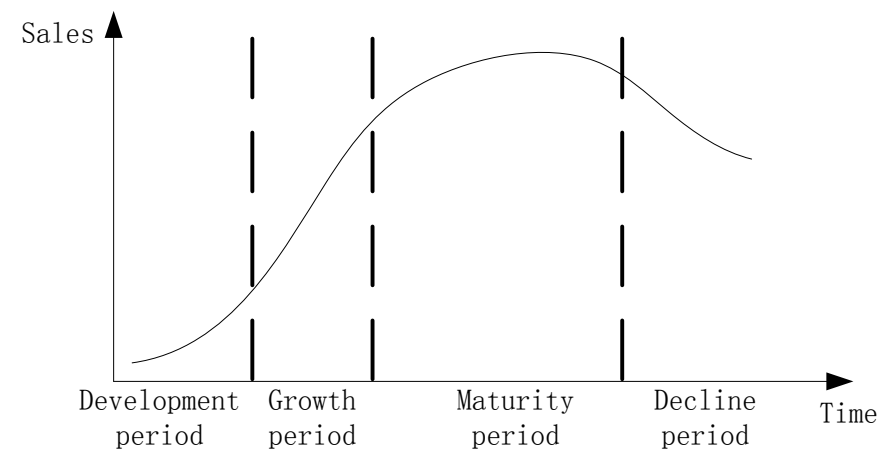

Fig. (1). The general concept of a product life cycle. 


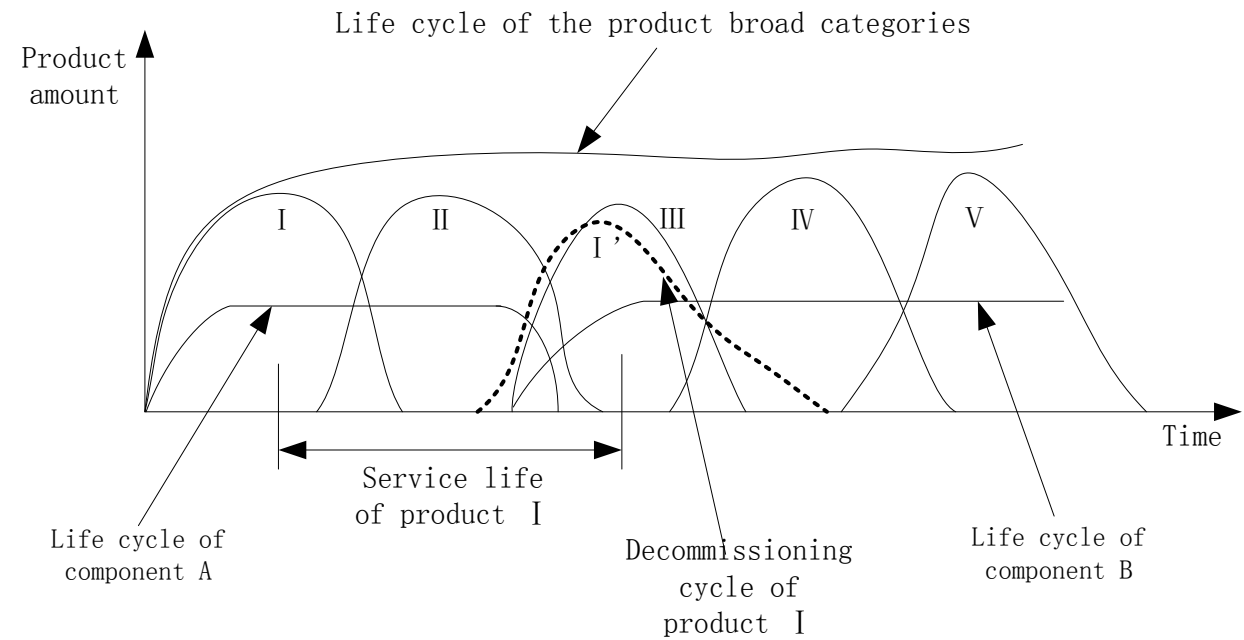

Fig. (2). Model of remanufacturing process based on the life cycle of products.

previous generation model, the new model is mainly redesigned and improved in the exterior, interior and configurations. In addition, the assembly and components may also be upgraded with the development of technology. However, the upgrade cycles of these components are generally longer than the upgrade cycles of the product subgeneration.

Regarding the service time of products, the service life cycle is generally longer than its market life cycle. The product begins to enter the decommissioning process after completing the service life. There is also a cycle phenomenon in its decommissioning process. The decommissioning period of the first-generation product is taken as an example, as represented by I' in Fig. (2). The period between the two peaks is the rated life of the product, and the climax of 'I' is also the peak time of decommissioning. Due to the early retirement of some products and the delayed retirement of some high-quality products, the distribution region of the product decommissioning cycle curve is larger than that of the market cycle curve. As can be seen from the product decommissioning cycle curve, the products sold during its decommissioning process may be either the products of the same generation or the upgraded products.

From the perspective of the customers' acceptance, if the product decommissioning occurred during the upgrading stage of the broad categories, such as replacing Walkman by MP3 player as mentioned above, there is no market potential in remanufacturing EOL products. If the product decommissioning is performed at the upgrading stage of product subgeneration, there may still be some market potential in remanufacturing.

\subsection{Remanufacturability Analysis Based on Market Life Cycle}

The model of product life cycle shown in Fig. (2) allows the analysis of remanufacturability, and thus involves the decision of remanufacturing strategies. The decision-making processes is demonstrated in Fig. (3). The remanufacturing of EOL products is divided into three cases in this study. In the first case, the EOL products and the mainstream products currently being sold in the market technically belong to the same generation, and the profit margin of the remanufacturing process still accord with the company's requirements. Then, the remanufacturing process can be conducted. If the EOL products and the current products are of different generations, a decision should be made on whether the products can be upgraded by replacing components. If the product's function can be upgraded and the cost-profit of the remanufacturing process accord with the requirements of enterprises, this EOL product then is able to re-enter the market after upgrading and remanufacturing. In the third case, when the product is not suitable for direct remanufacturing or upgrading remanufacturing, it needs to be determined whether the generic components or modules are of the same generation of products in the market. If they are of the same generation and the cost-profit analysis of remanufacturing accord with the business requirements, this case can be handled as a component remanufacturing.

\subsection{Remanufacturing Cost-Profit Analysis of Product Life Cycle}

From the perspective of remanufacturing enterprise, the cost-profit analysis of the remanufacturing process is a key factor to decide whether a EOL product can be remanufactured or not. From the basic flowchart of general product remanufacturing (as shown in Fig. 4), the cost model in the remanufacturing process can be defined as:

$$
C=n \cdot C R+n \sum_{i=1}^{q} C M_{i}+n \cdot \sum_{i=1}^{l} \rho_{i} \cdot C G_{i}
$$

where $n$ is the bulk number of EOL products; $C R$ is the collecting cost of waste products, including the costs of purchase and transportation; $C M_{i}$ is the cost of each step in remanufacturing process, and $q$ is the total number of the 


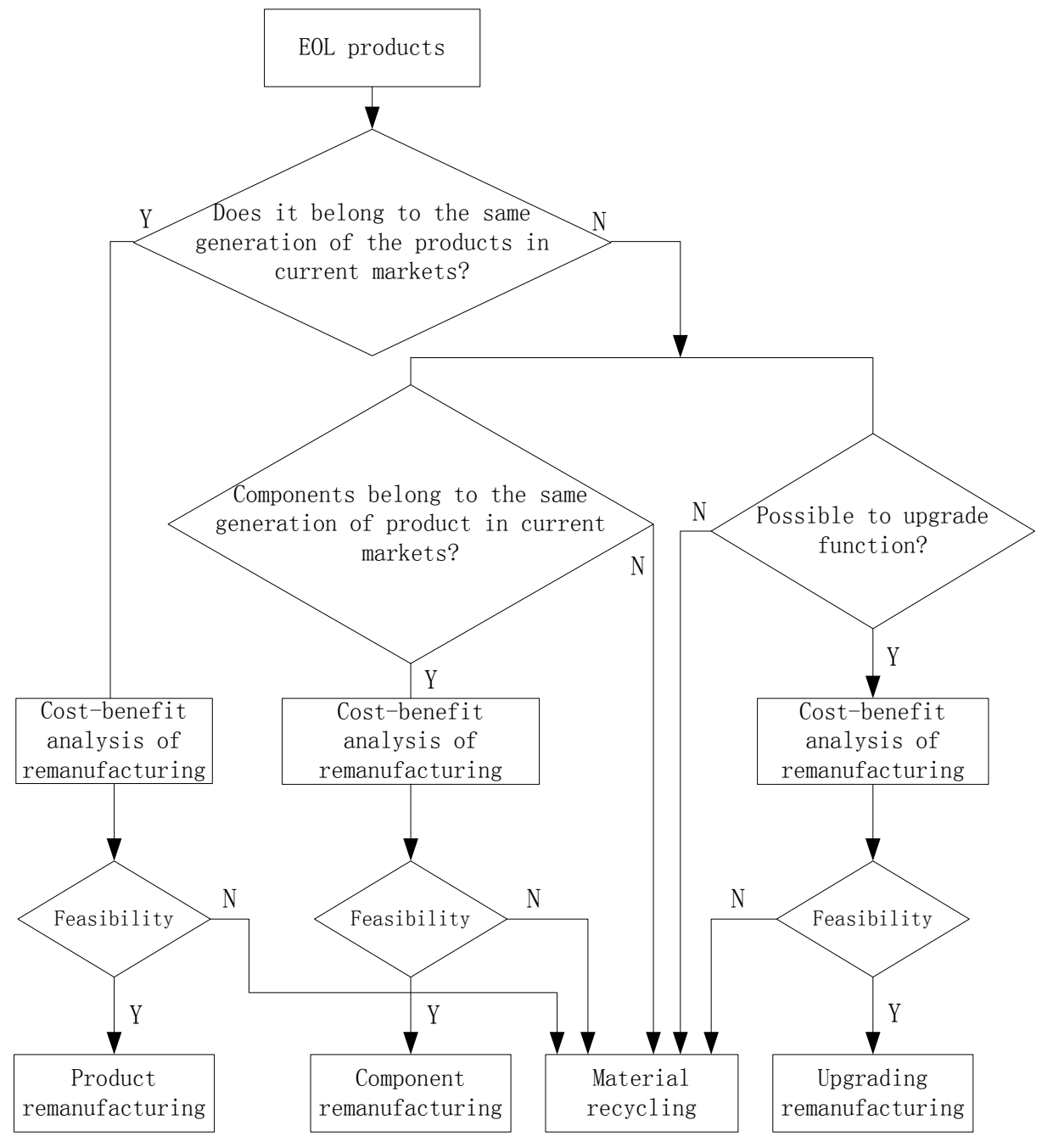

Fig. (3). Flowchart of selection remanufacturing strategy for EOL products.

remanufacturing processes. Since some components can not be reused again after dismantling, they need to be replaced by new components in the final assembly. The rate of breakage or failure is defined by a factor $\rho$. $C G_{i}$ is the cost for purchasing this new components or parts. For the remanufacturing of specific models and standard products, $\rho$ can be regarded as a constant.

Usually, remanufactured products cannot be sold at the price of new products. Instead, they are sold with a discount off the price of new products with the same specifications. The discount factor is defined as $\lambda . P_{m}$ is the market price of new products. The gross profit, defined as $P$, of a batch of remanufactured products is defined as:

$$
P=n \cdot P_{m} \cdot \lambda-C
$$

According to the general definition of gross profit, the gross profit rate $R$ of a batch of remanufactured product can be defined as:

$$
R=\frac{n \cdot P_{m} \cdot \lambda-C}{n \cdot P_{m} \cdot \lambda}
$$

Based on the constraint condition of a batch of remanufactured product, the benefits of the fixed costs (investment of equipment, workshop, etc.) can only be ensured when a certain number of products for remanufacturing are reached. This number is named as threshold of the economic batch and defined as $N$. thus, the bulk number $n$ should greater than threshold of the economic batch, that is, $n \geq N$. Where threshold $N$ of the economic batch can be determined according to the general method of technology economy.

For the aspect of upgrading remanufacturing. Besides above defined cost model, the costs for purchasing and replacing of functional components should be include. Thus, the cost model $C$ is expanded to:

$$
C=n \cdot C R+n \sum_{i=1}^{q} C M_{i}+n \cdot \sum_{i=1}^{l} \rho_{i} \cdot C G_{i}+n \cdot \sum_{i=1}^{m} C F_{i}
$$

where $C F_{i}$ is the purchasing cost of functional components. And $m$ is the number of type for functional components. 


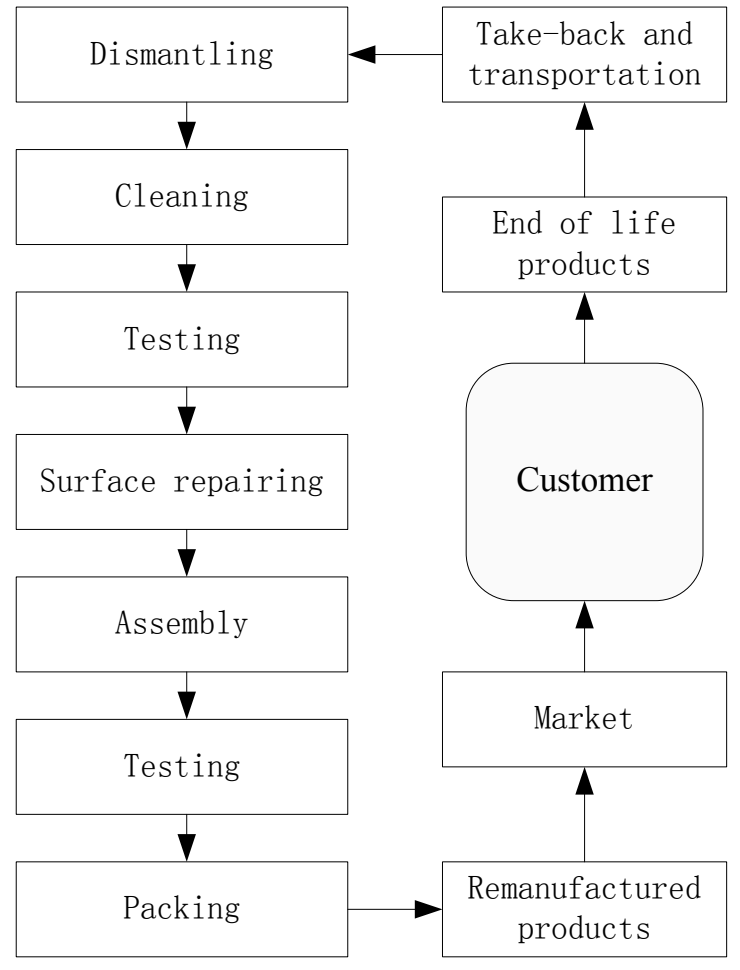

Fig. (4). Process of remanufacturing.

For the case of components remanufacturing, the process of remanufacturing is similar with the process of product remanufacturing. It must be emphasized that, because the profit margins of component remanufacturing is smaller then product remanufacturing, the automatic equipment used for remanufacturing are very important in the whole investment.
It is often called the fixed cost. Therefore, the bulk number $n$ is the key factor in the cost profit analysis for component remanufacturing.

\section{CASE STUDY}

With the above mentioned evaluating model of remanufacturability, several typical remanufacturing patterns of EOL products are analyzed bellow.

\subsection{Remanufacturing of Small Milling Machine}

Small milling machine is a commonly-used manufacturing equipment in small and medium enterprises. With increasing of service time, the guides, spindles and other parts may lose their accuracy. At a certain stage when the quality of machined parts is no longer guaranteed, the machine should be replaced by new one. In the case of the remanufacturing of small milling machine, which has relatively long market life cycle, its market share and profit margin have been significantly reduced. Although there is still a certain market space.

For EOL small milling machine, there are two possible remanufacturing strategies. One strategy is to restore its performance by direct refurbishing. The other is to upgrade, remanufacture and change it into a small CNC (Computer numerical control) milling machine by replacing the driven components with server motors and installing PC-based $\mathrm{CNC}$ system. The cost-profit parameters of direct remanufacturing is listed in Table $\mathbf{1}$, and the cost-profit parameters for upgrading remanufacturing is listed in Table 2.

Table 1. Cost-profit analysis of direct remanufacturing for milling machines.

\begin{tabular}{|c|c|c|c|c|}
\hline $\mathbf{C R}$ & $\mathbf{C M}_{\mathbf{i}}$ & $\mathbf{C G}$ & $\mathbf{P}_{\mathbf{m}}$ & $\mathbf{R}$ \\
\hline \hline 800 & $\mathrm{CM}_{1}$ dismantling: 600 & 520 & 11000 & \\
\hline & $\mathrm{CM}_{2}$ cleaning: 300 & & & \\
\hline & $\mathrm{CM}_{3}$ component remanufacturing: 3200 & & & \\
\hline & $\mathrm{CM}_{4}$ assembly: 600 & & & \\
\hline
\end{tabular}

Table 2. Cost-profit analysis of upgrading remanufacturing for milling machines.

\begin{tabular}{|c|c|c|c|c|}
\hline CR & $\mathbf{C M}_{\mathbf{i}}$ & $\mathbf{C F}$ & $\mathbf{P}_{\mathrm{m}}$ & $\mathbf{R}$ \\
\hline \multirow[t]{5}{*}{800} & $\mathrm{CM}_{1}$ dismantling: 600 & Adjustable speed motor 680 & 28500 & $43.6 \%$ \\
\hline & $\mathrm{CM}_{2}$ cleaning: 300 & Servo drive 6000 & & \\
\hline & $\mathrm{CM}_{3}$ component remanufacturing: 0 & Guide 580 & & \\
\hline & $\mathrm{CM}_{4}$ assembly: 1200 & CNC system software 2200 & & \\
\hline & $\mathrm{CM}_{5}$ testing: 500 & & & \\
\hline
\end{tabular}


Since CNC equipment are most popular used in the current manufacturing. And this type of product is just at the maturity stage on product life cycle curve. Thus, by the upgrading remanufacturing approach, the remanufactured small milling machine can be accepted by the customers. The market price of a type of small milling machine is 2850 RMB. Since the functional components used in this case are all new product, so, the discounting coefficient $\lambda$ is assumed to be 0.8 . And because the guides of EOL small milling machine can be replaced with new standard guides, thus the cost of surface repairing for guides is canceled. i.e., the $\mathrm{CM}_{3}$ in the Table 2 is 0 . According to the calculation, the gross profit rate of upgrading remanufacturing is $43.6 \%$.

From the above analysis, the gross profit rate of direct remanufacturing for small milling machine is $20.6 \%$, and it is $43.6 \%$ with upgrading remanufacturing. For this type of EOL products, the upgrading remanufacturing by component replacement and functional module upgrading is a more feasible approach. However, it should be emphasized that the employ of cost-effective functional components in upgrading remanufacturing is a critical method. e.g., CNC software used in this study significantly reduced the remanufacturing cost while accord with the requirements of users. If hardware based CNC is employed, the profit margin will decreased greatly.

\subsection{Remanufacturing of Vehicle Motors}

When a vehicle end of its life after long time using, the remanufacturing of whole vehicle is evidently unfeasible from the perspectives of market, security and legality. In addition, the development speed of automotive products is much more rapid than that of industrial equipment such as machine tools. Even if the remanufacturing is well performed, it is difficult for customers to accept the vehicle due to its out-of-date style. However, the internal interchangeable components have a relatively long market life cycle. Thus, these interchangeable components can be remanufactured. The remanufactured products can be sent to the repairing market or engine remanufacturing enterprises.

The vehicle motors, as general components with long technology life cycle, have a great market requirement. It can be recycled as component remanufacturing. The remanufacturing process of vehicle motors includes dismantling, testing, remanufacturing and re-assembly of components and testing of finished products. Some bearings and coils need to be replaced. Table $\mathbf{3}$ is the cost-profit analytical data of the remanufacturing process for a certain type of automobile motor, where the breakage rate of the bearing is $50 \%$ and the breakage rate of the coil is $28 \%$. The bulk number $n$ of remanufactured products is 60000 / year (the economic batch $\mathrm{N}$ is $10000 /$ year) and the discounting coefficient $\lambda$ is 0.9 .

As calculated from the data in Table $\mathbf{3}$, the remanufacturing gross profit rate of this type of vehicle motors is $35.2 \%$. It is known from the analysis that the remanufacturing of vehicle motors have a relatively good economic benefit. It must be explained that, this mainly due to the low price of EOL vehicle motors and the batch number for remanufacturing. Since the EOL vehicle motors come from the disassembly of end of life vehicle. The price of EOL motors almost equal to the price of waste material. Moreover, the component remanufacturing has the economic feasibility only when the EOL products have a considerable amount and the remanufacturing batch number is larger than its economic batch. Therefore, the component remanufacturing is difficult to ensure the economic feasibility for those niche products at lower amount.

\subsection{Remanufacturing of Cell Phones}

Cell phone belong to consumptive electron product. According to standard, the service life of a cell phone should more than three years based on the design parameter. But on the market of smart cell phone, the market life cycle of a type of product often not more then one year. One type of product is usually replaced by new product due to the outdated performance parameters and functional characteristics. Therefore, generally there is no market space for reselling old smart cell phones after remanufacturing. Although the upgrading of functional accessories of old cell phones, i.e., upgrading remanufacturing, is theoretically possible, the cost of remanufacturing would be significantly higher than that of fabricating new products. This mainly because the degree of automation of equipment used in the remanufacturing processes is much more lower than that in the original manufacturing process. We assume that one type

Table 3. Cost-profit analysis of the remanufacturing of vehicle motors.

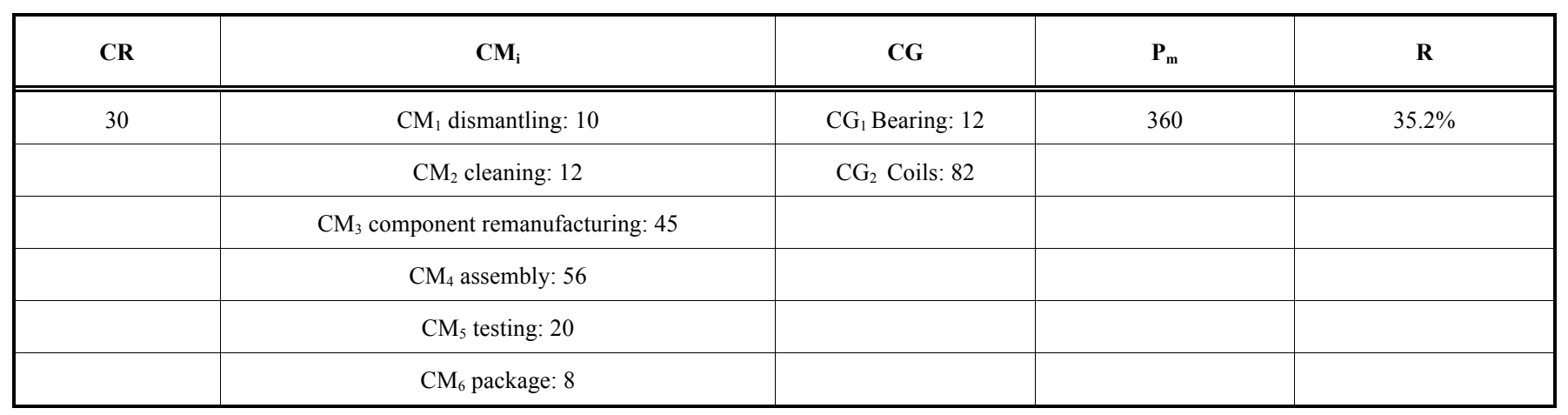


Table 4. Cost-profit analysis of the remanufacturing of cell phones

\begin{tabular}{|c|c|c|c|c|c|}
\hline CR & $\mathbf{C M}_{\mathbf{i}}$ & $\mathbf{C G}$ & $\mathbf{C F}$ & $\mathbf{P}_{\mathbf{m}}$ & $\mathbf{R}$ \\
\hline \hline 30 & $\mathrm{CM}_{1}$ dismantling: 120 & 45 & 326 & 980 & $-20.5 \%$ \\
\hline & $\mathrm{CM}_{2}$ cleaning: 10 & & & \\
\hline & $\mathrm{CM}_{3}$ component remanufacturing: 0 & & & \\
\hline & $\mathrm{CM}_{4}$ assembly: 180 & & & \\
\hline & $\mathrm{CM}_{5}$ testing: 65 & & & \\
\hline
\end{tabular}

of smart cell phone could be remanufactured with upgrading remanufacturing approach. Under the premise of circuit compatibility, the camera unit and the CPU unit is replace by new type of component. And the cases of cell phone are replace by new one. The bulk number $\mathrm{n}$ is predefined as 30,000 here. Other data is listed in the Table 4.

In this case, the dismantling of waste smart cell phone includes the deassembly the structure of phone and the components from the printed circuit board. The operation of re-welding the chip on the board mainly relies on manual methods and special tools, and this leads to a higher cost. CG in Table 4 refers to the old case of smart cell phone should be replaced by new one; therefore, the coefficient $\rho$ is 1 . Due to the low attractiveness of such remanufactured electronic products to the customers, its price discounting coefficient $\lambda$ is 0.65 . At last, the gross profit rate is negative as calculated from the data in Table 4. Therefore, there is no feasibility for remanufacturing the waste smart cell phone at all. Although the display and the touch screen components have the value of reuse, there are still many barriers in specific technical aspects. Taken together, the most suitable approach for recycling used smart cell phone is material recycling, that is, by shredding and sorting technology, and extracting the precious metal from the scrap of smart cell phone with special technology.

\section{CONCLUSION}

In this paper, the life cycle of product is divided into the concept of market life cycle, service life cycle, technology life cycle and decommissioning life cycle. By this means, the model of remanufacturing based on the product life cycle is presented. For the aspect of recycling of end of life products, only valuable product or component which can be accepted by the customer is feasible for remanufacturing. The others can be disposed by material recycling. To this end, the costprofit analysis approach is proposed for remanufacturing. By analyzing the cost of remanufacturing and the acceptable price of refurbished product on the market, the optimized strategy of remanufacturing of end of life products can be determined.

However, the strategy proposed in this paper only provides some hints to the decision maker of remanufacturing. Since some of the factor is neglected or simplified. i.e., the returning of end of life product is affected by many uncertainties, such as living standard, custom, policy and so on. That is, the cost of remanufacturing is determined by the quantity of returned end of life product to a certain extent. Especially, the degree of automation of remanufacturing will also affects the result of cost and profit analysis. Furthermore, the decision tool and related database is need to be developed for engineering application.

\section{CONFLICT OF INTEREST}

The authors confirm that this article content has no conflict of interest.

\section{ACKNOWLEDGEMENT S}

This work was financially supported by the 333 High Level Talent Engineering of Jiangsu Province of China (No. BRA2012158). Jiangsu Science \& Technology Pillar Program of China (No. BE2013060). Suzhou Science \& Technology Program of China (No. SGZ2013124).

\section{REFERENCES}

[1] Y. Liu, B. Xu, P. Shi, and B. Liu, "Assessment indexed of used products remanufacturability," China Surface Engineering (In Chinese), vol. 24, no. 5, pp. 94-99, 2011.

[2] S. Ramesh, D Huisingh, R. B. Chinnam, and S. Subramoniam, "Remanufacturing Decision-Making Framework (RDMF): research validation using the analytical hierarchical process," Journal of Cleaner Production, vol. 40, no. 9, pp. 212-220, 2013.

[3] Y. Du, H. Cao, F. Liu, C. Li, "Process model of machine too remanufacturing oriented to lifecycle," Computer Integrated Manufacturing Systems (In Chinese), vol. 16, no. 10, pp. 20732077, 2010.

[4] M. Lindahl, E. Sundin, and J. Ostlin, "Environmental issues with the remanufacturing industry," In: Proceedings of the $13^{\text {th }}$ CIRP international conference on Life Cycle Engineering, Katholieke Universiteit Leuven, Belguim, 2006.

[5] M. S. Skrainka, "Analysis of the Environmental Impact on Remanufacturing Wind Turbines," Master' s Degree Thesis, Rochester Institute of Technology, http://scholarworks.rit.edu/cgi/ viewcontent.cgi? article $=6686 \&$ context $=$ theses

[6] Z. Ghazalli, and M. Atsuo, "The development of the computer aided remanufacturing system (CARES) part i: software development (phase I) and a simulation study," $5^{\text {th }}$ International Workshop on Computational Intelligence \& Applications. Hiroshima University, Japan, November, 2009.

[7] S. Sabharwal, and S. Garg, "Determining cost effectiveness index of remanufacturing: A graph theoretic approach," International 
Journal of Production Economics, vol. 144, no. 4, pp. 521-532, 2013.

[8] G. Zhang X. Jing, G. Pu, C. Wang, and B. Xu, "The assessment method and model of remanufacturability," Journal of Shanghai Jiaotong University (In Chinese), vol. 39, no. 9, pp. 1431-1436, 2005.

[9] H.B. Lee, N.W. Cho, and Y.S. Hong, "A hierarchical end of life decision model for determining the economic levels of remanufacturing and disassembly under environmental regulations," Journal of Cleaner production, vol. 18, no. 9, pp. 1276-1283, 2010.

[10] S.B. Dixit, Product design: A conceptual development of product remanufacturing index. http://scholarcommons.usf.edu/cgi/ viewcontent.cgi?article $=3503 \&$ context $=$ etd

[11] M. R. Johnson, and I. P. McCarthy, "Modeling the uncertainty of the remanufacturing process for consideration of extended producer responsibility (EPR)," http://waset.org/publications/6139/modeling-theuncertainty-of-the-remanufacturing-process-for-consideration-ofextended-producer-responsibility-epr-

[12] K. Gao, P. Nagaratnam, T. Chua, "Hybrid discrete harmony search algorithm for scheduling re-processing problem in remanufacturing", Proceedings of the $15^{\text {th }}$ Annual Conference on Genetic and Evolutionary Computation, New York, NY, USA 2013.7

[13] A. Boustani, S. Sahni, S. C. Graves, T.G.Gutowski. "Appliance remanufacturing and life cycle energy and economic savings". http://www.reman.org/articles/appliance_reman.pdf

[14] F. Azadivar, S. Ordoobadi, "A simulation model to justify remanufacturing policies, Proceedings of the Winter Simulation Conference, Baltimore, Maldives, 5-8 Dec. 2010.

(C) Ziqiang et al.; Licensee Bentham Open.

This is an open access article licensed under the terms of the (https://creativecommons.org/licenses/by/4.0/legalcode), which permits unrestricted, noncommercial use, distribution and reproduction in any medium, provided the work is properly cited. 